\title{
Creep Characteristics of Ag-4 wt\% Cu Alloy at High Stresses
}

\author{
A. Fawzy, M.T. Mostafa and F. Abd El-Salam \\ Department of Physics, Faculty of Education, \\ Ain Shams University, Cairo, Egypt.
}

\begin{abstract}
Creep characteristics of $\alpha$-solid solution Ag-4 wt\% Cu alloy samples of different grain diameters have been investigated under high stresses ranged from 151-193 Mpa at RT. The creep results showed that the transient creep parameter $n$ increases linearly with grain diameter $d$, while $\beta$ varied with $d^{2}$ according to an empirical relation $\beta=\beta_{o}+k d^{2}$. This was explained on the basis of internal dislocation processes associating the creep deformation. A critical stress, $\sigma_{c}$, needed for initiating the creep process was observed from the dependence of $\beta$ on $\sigma$. The steady state rate $\dot{\varepsilon}_{s}^{\bullet}$ was found to vary with $d$. The stress exponent $m^{*}$ varied linearly with grain diameter. The obtained higher values of $m^{*}$ were attributed to the transition of the velocity of dislocation climb from a linear to an exponential function of stress. The dependence of $\dot{\varepsilon}_{s}^{\bullet}$ on $\beta$ was found to be valid with the exponent $\gamma$ which has a value of 0.6.
\end{abstract}




\section{Introduction}

One of the micro-structural factors known to affect transient and steady state creep behaviour is grain size [1]. During a creep test, grain boundaries may contribute to strengthening or weaken of a material depending on the working temperature and the applied stress. For creep testing at a low temperature and high stress, grain boundaries are capable of strengthening the materials. As a measure of this strengthening, it has been demonstrated that for stresses above a critical value the steady state creep rate $\varepsilon_{s}^{\bullet}$ varies as $\mathrm{d}^{2}$, where $\mathrm{d}$ is the grain diameter [2,3]. This result was explained by proposing that grain boundaries limit the distance which dislocation travels in slip bands. In creep experiments on $\mathrm{Cu}-10 \mathrm{wt} \% \mathrm{Sn}$ alloy, it was found [4] that $\varepsilon_{s}^{\bullet}$ increased with grain size for all applied stresses and temperatures. This was rendered to the effect of Sn addition on the nature of grain boundaries obtained during grain growth. On the contrary, it was found [5] that $\varepsilon_{s}^{\bullet}$ decreased by increasing grain size in $\mathrm{Sn}-\mathrm{Sb}$ solid solution alloy. It was reported [6] that $\varepsilon_{s}^{\bullet}$ of Al-10 wt\% Zn alloy was related to grain size according to a Petch type relation. There are comparatively few investigations [7] on the effect of stress changes on the creep behaviour of solid solution alloys. The stress dependence of creep behaviour of solid solution alloys showed two classes according to the value of the stress exponent $\mathrm{m}^{*}$. In class I alloys, $\mathrm{m}^{*}$ has a value of $\sim 3$, while for class II alloys $\mathrm{m}^{*}$ is similar to that of pure metals and is closer to 5 . However, at high normalized stresses $\left(\sigma / \mathrm{G}>10^{-4}\right.$, where $\sigma$ is the applied stress and $\mathrm{G}$ is the shear modulus), the creep rates $\left(\varepsilon_{s}^{\bullet}\right)$ increase rapidly with the stress to higher values and $m^{*}$ tends to values higher than $8[8,9]$. It was found [10] that the steady state creep rate $\varepsilon_{s}^{\bullet}$ of Al obeys a power law with a stress exponent $\mathrm{m}^{*} \cong 8$ in the low stress range. Also, the creep rate was described by an exponential dependence of stress [11]. For Al- $1 \mathrm{wt} \% \mathrm{Si}$ and Al-1 wt $\% \mathrm{Si}-0.1 \mathrm{wt} \% \mathrm{Zr}-0.1 \mathrm{wt} \% \mathrm{Ti}$ alloys $\mathrm{m}^{*}$ was found [9] to be generally high and assumed values in the range of 20-34 and 14-19 for the two alloys, respectively.

In view of these conflicting results and importance of silver -copper alloys, which did not receive enough attention concerning the effect of grain size on their creep behaviour, it was aimed to investigate the solid solution state of Ag-4wt.\% $\%$ u alloy to elucidate further the influence of grain size on its creep resistance at high normalized stress range. 


\section{Experimental Procedure \\ Material Preparation}

Ag-4 wt $\% \mathrm{Cu}$ alloy was prepared from pure copper and silver (99.99\%) by melting in a graphite crucible. Casting was done in a cylindrical graphite mold and the received cast was obtained in the form of rod $12 \mathrm{~mm}$ in diameter. It was homogenized at $700^{\circ} \mathrm{C}$ for 7 days, swaged and cold drawn in steps with intermediate annealing at $600^{\circ} \mathrm{C}$ for $1 \mathrm{hr}$. The resulting test specimens were in the form of wires of $0.3 \mathrm{~mm}$ in diameter. Specimens of different grain diameters were prepared by annealing them for $1 \mathrm{hr}$ at temperatures ranging from $700^{\circ} \mathrm{C}$ to $820^{\circ} \mathrm{C}$ followed by water quenching. To reveal the grain boundaries, after polishing the specimen, a solution of $\mathrm{HNO}_{3}$ and glacial acetic acid was used as an etchant. Specimens of the average grain diameters $80,90,105$ and $130 \mu \mathrm{m}$ were obtained. Measurements of grain diameter were carried out by using the linear intercept method and measuring approximately 30 intercepts.

\section{Mechanical Tests}

The tested specimens were subjected immediately after quenching to creep deformation by using a conventional constant load creep testing machine [12] in air at RT $\left(27^{\circ} \mathrm{C}\right)$. The creep tests were performed under the stresses $135,143,151,159,167,175,183$ and $193 \mathrm{MPa}$ by loading the test wire of the same grain diameter with corresponding stresses. The extension in the wire during creep was measured with an accuracy of $10^{-4} \mathrm{~cm}$. Not less than three creep tests were repeated for each grain diameter.

\section{Results}

The strain - time curves for specimens having different grain diameters obtained under different applied stresses are shown in Fig.(1). Each of the creep curves comprises a transient stage with decreasing creep rate and a steady state stage with a constant creep rate. In the present investigation failure was not reached for the tested samples. According to the transient creep equation:

$$
\varepsilon_{t r}=\beta t^{n}
$$

Straight lines relating $\ln \varepsilon_{t r}$ against lnt values, as deduced from Fig. (1), are given in Fig.(2). The exponent $\mathrm{n}$ increased from 0.3 to 0.55 with increasing grain diameter $d$. The second creep parameter $\beta$ in equation (1) was obtained from the intercept of the straight lines of Fig.(2) at $\operatorname{lnt}=0$. The 


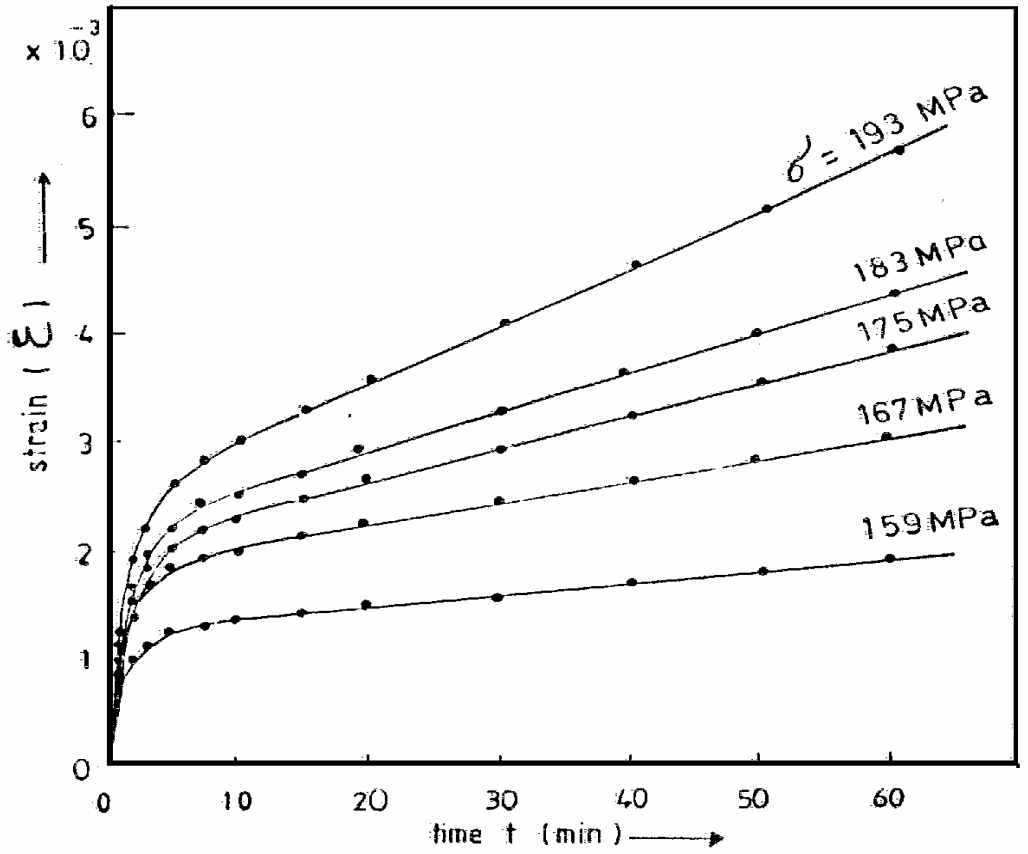

Fig.(1): Representative strain-time relation at RT for Ag-4 wt\% $\mathrm{Cu}$ wires with different grain diameters. The applied stress is indicated on each curve.

parameter $\beta$ was also found to depend on the grain diameter $d$. The stress dependence of the parameter $\beta$ is given in Fig. 3. It is clear that $\beta$ increases by increasing $\mathrm{d}$ and / or $\sigma$. The stress dependence of the steady state creep rate $\varepsilon_{s}^{\cdot}$, as calculated from the slopes of the linear parts of Fg.1, for samples with different grain diameters is given, as a relation between $\ln \varepsilon_{s}^{\bullet}$ and $\ln \sigma$, in Fig.4. The straight lines of Fig.4 satisfy the relation $\varepsilon_{s}^{\bullet}=\mathrm{A} \sigma^{\mathrm{m}^{*}}$. The slopes of these lines give the stress exponent $\mathrm{m}^{*}$, which assumed values ranging from 8 to 15.2 , depending on the grain diameter $\mathrm{d}$.

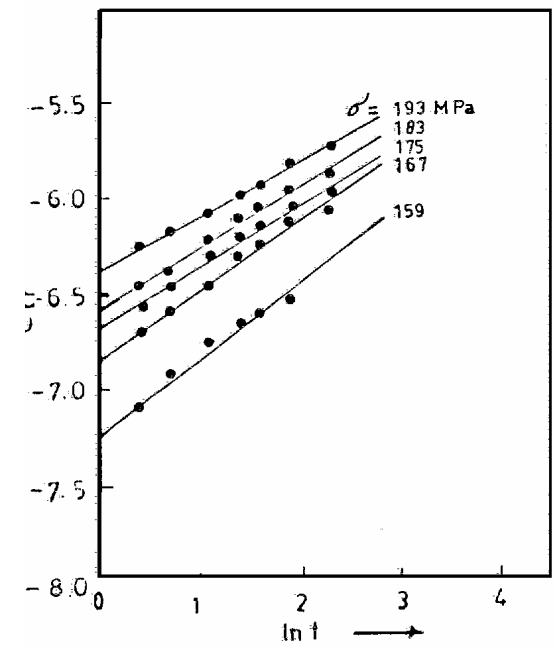

Fig.(2): Representative example for the relation between $\ln \varepsilon_{\mathrm{tr}}$ and $\operatorname{lnt}$ for $\mathrm{Ag}-4 \mathrm{wt} \% \mathrm{Cu}$ wires with different grain diameters. The applied Stresses are indicated. 


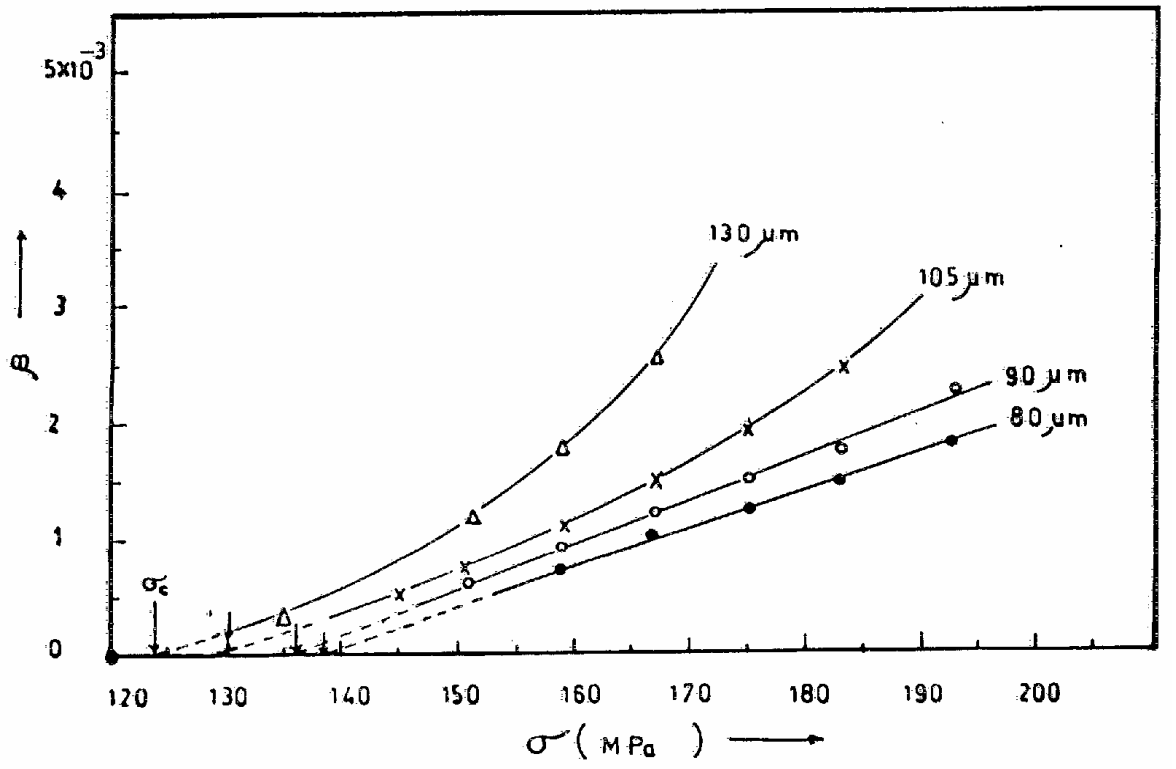

Fig.(3): The dependence of the transient creep parameter $\beta$ on the applied stress $\sigma$ for $\mathrm{Ag}-4 \mathrm{wt} \% \mathrm{Cu}$ wires with the different grain diameters indicated on each curve.

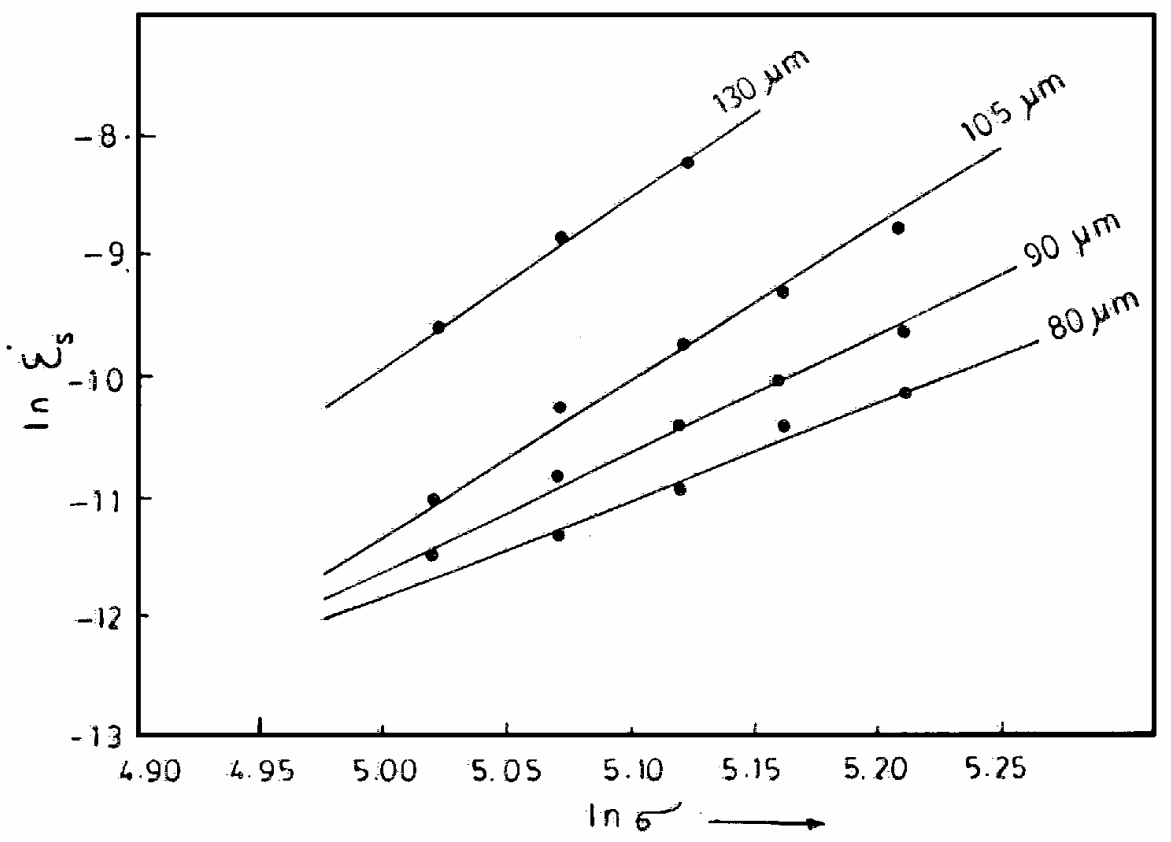

Fig.(4): The relation between $\ln \varepsilon_{s}^{\dot{*}}$ and $\ln \sigma$ for $\mathrm{Ag}-4 \mathrm{wt} . \% \mathrm{Cu}$ alloy Samples with the different grain diameters indicated on each curve. 
Discussion

Transient Creep

It has been established that increasing grain diameter leads [12] to a decrease in the mobile dislocation density $\rho$. According to the relation:

$$
\rho=\sigma_{\mathrm{i}}{ }^{2} /(\mathrm{nGb})^{2}
$$

where $b$ is the Burgers vector of the dislocation involved [13, 14], the transient creep parameter $\mathrm{n}$ determines the dependence of the mobile dislocation density $\rho$ on the average internal stress $\sigma_{\mathrm{i}}$ and the shear modulus G. At high normalized stresses $\left(\sigma / \mathrm{G}>10^{-4}\right)$, and since the internal stress $\sigma_{\mathrm{i}}$ is a small fraction of the applied stress $\sigma$, it can be assumed that $\sigma_{i}$ is constant [14]. In view of this, the increase in grain size decreases the mobile dislocation density $\rho$. Consequently, the transient creep parameter $\mathrm{n}$ should increase with increasing grain diameter. This finding agrees with previous results [12].

The increasing values of $\beta$ with increasing both grain diameter and stress Fig. 3 can be explained on the basis of internal processes associating the creep process. These internal processes involve a redistribution of dislocations in the networks, the formation of new Frank - Read sources and, the creation of point defects during the creep process [15]. These created lattice defects might increase the recovery process leading to the observed increase of the transient creep parameter $\beta$.

The stress dependence of $\beta$ Fig. (3) shows that there is a critical stress $\left(\sigma_{c}\right)$ at which the creep process starts. Increasing grain diameter, which is associated with a decrease in internal stresses, leads to a decreasing $\sigma_{c}$ values. The linear dependence of $\sigma_{c}$ on grain diameter given in Fig.5 shows that internal stresses are expected to vanish at a grain diameter determined as the intercept, if the linear dependence of $\sigma_{\mathrm{c}}$ dominates up to this grain diameter value.

\section{Steady State Creep}

The steady-state creep rate $\left(\varepsilon_{s}^{\bullet}\right)$ values, obtained from the linear parts in Fig.1, were found to depend on grain diameter $d$ and the applied stress $\sigma$, Fig. (4). When different grain diameters with minimum grain growth such that misorientation of grain boundaries is randomly distributed [16], the steady state creep rate $\varepsilon_{s}^{\bullet}$ should increase with increasing grain diameter [12]. This is due to the lower degree of boundary misorientation in large grains. Hence, blocking of dislocation motion would be less and the increase 
of $\dot{\varepsilon}_{s}^{\bullet}$ with grain size observed in Fig.6 can therefore be explained. This agrees with previously obtained results $[2,17,18]$.

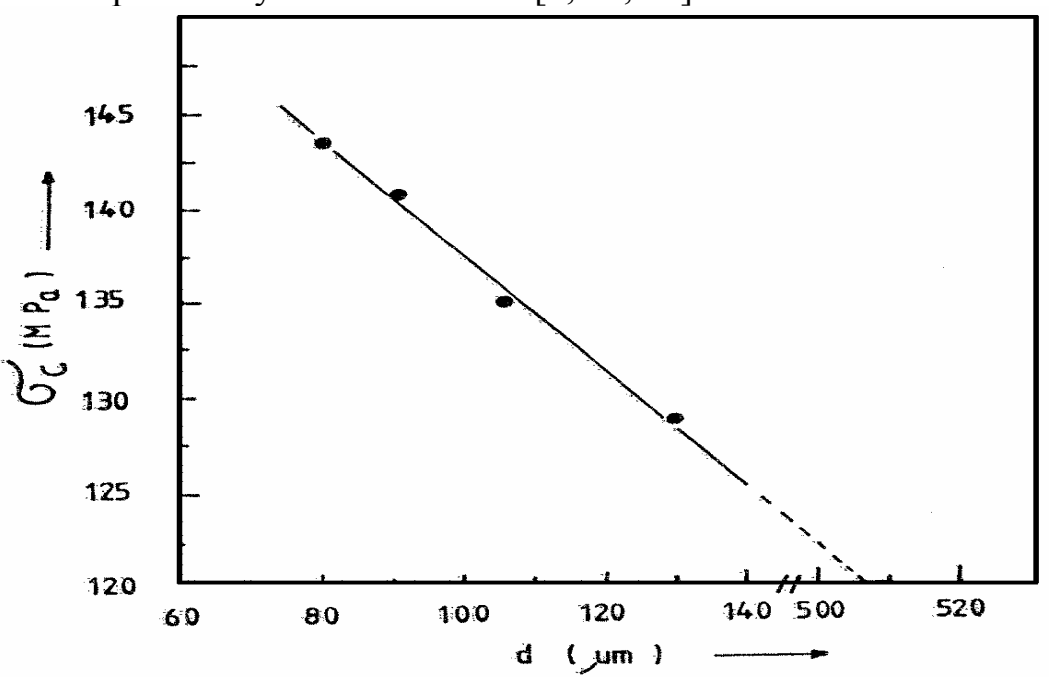

Fig.(5) : The relation between critical stress $\sigma_{\mathrm{c}}$ and grain diameter $\mathrm{d}$.

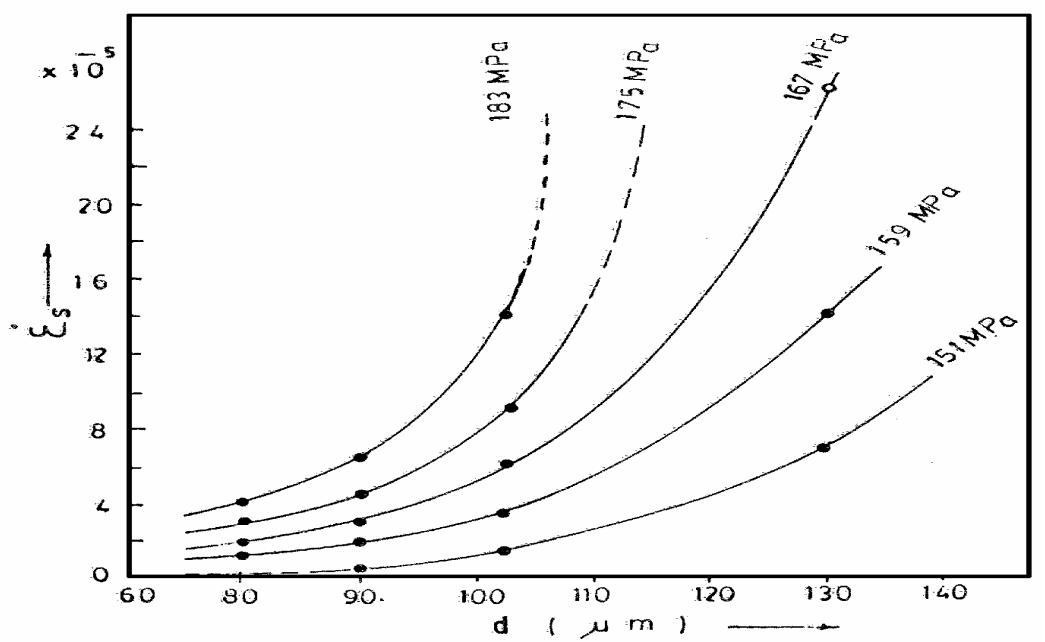

Fig.(6): The dependence of the steady state creep rate $\varepsilon_{S}^{\bullet}$ on the grain Diameter $\mathrm{d}$ for Ag$4 \mathrm{wt} \% \mathrm{Cu}$ alloy samples. The applied stress is Indicated on each curve.

The steady state creep rate $\varepsilon_{s}^{\bullet}$ in pure metals and metal type alloys (class II) is controlled by the climb of dislocations in the power law region. In the present investigation, the power-law creep was found to be valid and $\ln \varepsilon_{s}^{\bullet}$ is linearly related with $\ln \sigma$ for the specimens of different grain diameters, see Fig. (4). The values of the stress exponent $\mathrm{m}^{*}$, calculated 
from fig. 4 showed a linear dependence on grain diameter $\mathrm{d}$ consisting with the empirical relation;

$$
\mathrm{m}^{*}=\mathrm{m}_{\mathrm{o}}^{*}+\chi \mathrm{d}
$$

where $\mathrm{m}^{*}$ and $\chi$ are experimental constants. The calculated values of the constants $\mathrm{m}^{*}$ and $\chi$ assumed the values 0 and 0.065 respectively, at $\mathrm{d}=25$ $\mu \mathrm{m}$. The large values of $\mathrm{m}^{*}(8-15.2)$ may be explained as being due to the transition [6] of the velocity of dislocation climb from a linear form to an exponential function of stress at that level of stress used in this work. This is expected when the applied stress reaches a value at which the dislocations can break away from their solute atmospheres $[6,19,20]$.

A correlation between creep stages can be attained through the exponent $\gamma$ from the relation:

$$
\beta=\beta_{o}\left(\varepsilon_{s}^{\bullet}\right)^{\gamma},
$$

where $\beta$ is the transient creep parameter and $\varepsilon_{S}^{\bullet}$ is the steady state creep rate.

The linear dependence relating $\beta$ and $\varepsilon_{s}^{\bullet}$ given in Fig. (7) shows a grain diameter independence of the ratio $\gamma$. The ratio $\gamma$ assumed an average value of 0.6 . The dependence of $\varepsilon_{s}^{\bullet}$ on $\beta$ seems to be due to the decrease of dislocation density to a level that makes the hardening rate at the end of the transient stage converges to recovery rate. So, the steady state creep starts with rates depending on the applied stress and the grain diameter of the samples.

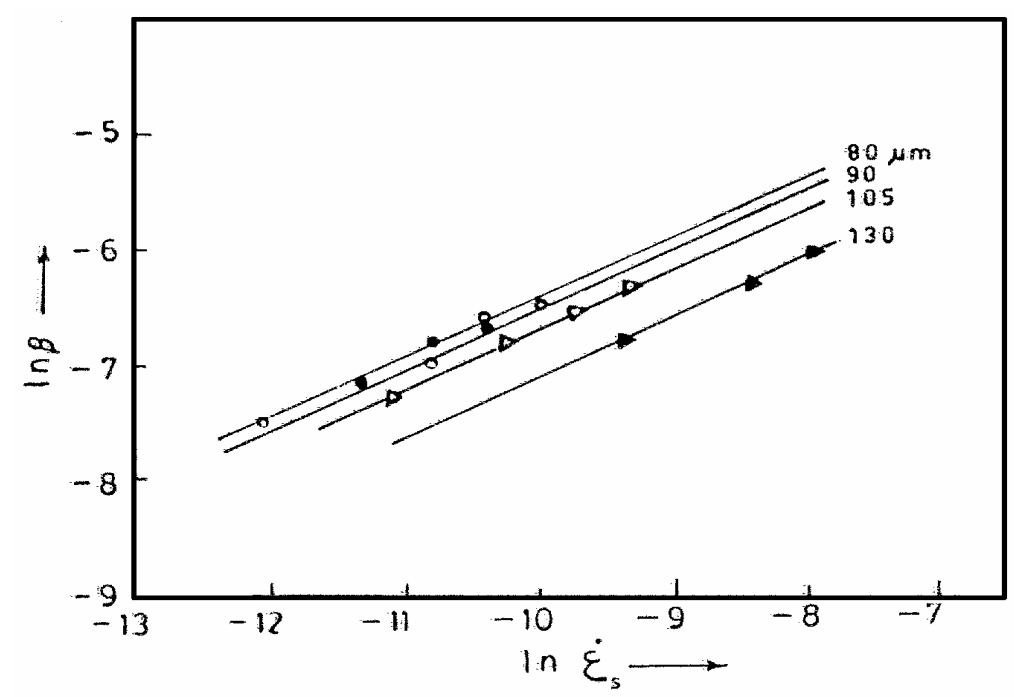

Fig.(7): The relation between the transient creep parameter $\beta$ and the Steady state creep rate $\varepsilon_{s}^{\bullet}$. 


\section{References}

1. Garofalo, F.; "Fundamentals of Creep and Creep Rupture in Metals", McMillan, New York, 1965.

2. Feltham, P., Copley, G.J.; Phil. Mag.; 5 (1960) 649.

3. Sherby, O..D.; Acta Met.; 10, 135 (1962).

4. Graiss, G., Saad, G., Fawzy, A., Kenawy, M.A.; Czeh, J., Phys., 41, 149 (1991).

5. Saad, G.; Abd El-Salam, F.,Mostafa, M.T., Surface Technology, 22, 73 (1984).

6. Youssef, S.B., Fawzy, A., Sobhy, M., Saad, G., Acta Phys. Slov., 43, 431 (1993).

7. Mohamed, F.A., Langdon, T.G., Acta. Metall. 22, 779 (1974).

8. Mohmoud, S., Soliman; J. Mater. Sci, 22, 3529 (1987).

9. Deaf, G.H., Beshai, M.H.N., Abd-El Khalik, A.M., Graiss, G., Kenawy, M.A; Cryst. Res. Technol. 3, 32, 423 (1997).

10. Sherby, O.D., Klundt, R.H., Miller, A.K.; Metall. Trans., 8A, 843 (1977).

11. Yoney, D.T., Gibeling, J.C. and Nix, W.D.; Acta Metall. 35, 1391 (1987).

12. Youssef, S.B., Fawzy, A., Sobhy, M., Saad, G.; Cryst. Res. Technol., 30, 7 (1995).

13. Gilman, J.J.; J. Apl. Phys.; 36, 2772 (1985).

14. Edington, J.W., Smallman, R.E.; Acta Metall., 12, 313 (1964).

15. Al-Ganainy, G.S.; Egyptioan J. Sol., 18, 2, 345 (1995).

16. Parker, E.R.; Proc. Ann. Soc.; Testing Mater, 60, 849 (1960).

17. Feltham P.; Proc. Phys. Soc. London B69, 1173 (1956).

18. Feltham, P. And Meakin, J.D.; Acta Met. 7, 614 (1959).

19 Weertman, J.; "Rate Processes in Plastic Deformation of Materials". Edited by J.C.M.L. Mukherjee A.K. (ASM, Metal Park, Ohio, P315 (1975).

20. Mohamed, F.A., Mater. Sci. Eng., 38, 73 (1979). 